\title{
Prone percutaneous nephrolithotomy: its advantages and our technique for puncture
}

\author{
Diego M. Carrion ${ }^{1}$, José Ramón Cansino ${ }^{1,2}$, Luis M. Quintana ${ }^{1}$, Juan Gómez Rivas ${ }^{1,2}$, Juan Antonio \\ Mainez Rodriguez ${ }^{1}$, José Ramón Pérez-Carral ${ }^{1}$, Luis Martínez-Piñeiro ${ }^{1,2}$ \\ ${ }^{1}$ Department of Urology, La Paz University Hospital, Madrid, Spain; ${ }^{2}$ La Paz University Hospital Institute for Health Research (IdiPAZ), Madrid, Spain \\ Contributions: (I) Conception and design: All authors; (II) Administrative support: All authors; (III) Provision of study materials or patients: All \\ authors; (IV) Collection and assembly of data: All authors; (V) Data analysis and interpretation: All authors; (VI) Manuscript writing: All authors; (VII) \\ Final approval of manuscript: All authors. \\ Correspondence to: Diego M. Carrion. Department of Urology, La Paz University Hospital, Paseo de la Castellana 261, Madrid 28046, Spain. \\ Email: diegocarrionm@hotmail.com.
}

\begin{abstract}
Percutaneous nephrolithotomy (PCNL) is considered the treatment of choice for large urinary calculi and staghorn lithiasis. The approach for this surgery may be either supine or prone, and different access techniques are described in the literature with the use of ultrasound, fluoroscopy, or both combined. We believe that prone PCNL offers to the urologist key advantages, such as the possibility of puncturing anatomically abnormal urinary tracts, to perform multiple percutaneous tracts in the same kidney, experiencing the vacuum cleaner effect, ease of exploring the upper calyx through the inferior calyx, possibility to perform endoscopic combined intrarenal surgery (ECIRS) and bilateral simultaneous surgery, and to performed over local anesthesia. An adequate training for the endourologist should include both the prone and supine techniques for PCNL and to know which patient can benefit the most from each one.
\end{abstract}

Keywords: Prone; percutaneous nephrolithotomy (PCNL); staghorn lithiasis; fluoroscopy; urinary calculi

Submitted Jul 01, 2018. Accepted for publication Oct 15, 2018.

doi: $10.21037 /$ tau.2018.10.04

View this article at: http://dx.doi.org/10.21037/tau.2018.10.04

\section{Introduction}

Percutaneous renal surgery is considered one of the greatest advances in the field of minimally invasive urologic procedures. Since the first successful removal of renal calculi by percutaneous nephrolithotomy (PCNL), published in 1976 by Fernström and Johansson (1), the application of this technique became a popular approach for more applications, such as: draining hydronephrotic kidneys, resection of urothelial tumors and endopyelotomy. Later, the standardization of the technique by Alken et al. (2) and Segura et al. (3), and the first large series of cases reported in the literature $(4,5)$ promoted its implementation worldwide.

Proper indications in the management of stone disease have changed over time due to the introduction of techniques such as extracorporeal shockwave lithotripsy
(ESWL) and flexible ureterorenoscopy (fURS). Currently, the former treatment options (ESWL and fURS) have demonstrated limitations regarding the treatment of renal calculi greater than $20 \mathrm{~mm}$ (6), and renal PCNL has regained its popularity thanks to the possibility of using reduced calibers and modern, more efficient intracorporeal lithotripter modalities. In the present time, we have available calibers ranging from 4.8 to $30 \mathrm{Fr}$.

To two basic advances for the evolution technique: the reduction of the tract calibers (from 4.8 to $30 \mathrm{Ch}$ ), and the development of modern, more efficient intracorporeal lithotripters that can be used in such reduced calibers.

\section{Indications and contraindications of PCNL}

According to the EAU and AUA guidelines, the main indications for PCNL are renal stones greater than $20 \mathrm{~mm}$, 
which include staghorn and partial staghorn calculi $(6,7)$. Larger stones in the lower pole are also best managed by PCNL, which is also considered to be a gold standard in the management of calyceal diverticular stones, due to its higher stone-free rates with similar recurrence and complication rates in comparison with $\operatorname{ESWL}(8,9)$.

Contraindications for PCNL are pregnancy, bleeding diathesis, untreated urinary tract infection, tumor in the presumptive access tract area, and potential malignant kidney tumors (6).

\section{Anatomical considerations for percutaneous puncture}

Some of the most relevant descriptions of kidney vascular anatomy were published by Sampaio and cols (10-12). The authors suggested that a percutaneous puncture outside of the papilla increases the risk of hemorrhagic complications as it can easily puncture intraparenchymal arteries (10-12).

In a recent publication, Escovar Díaz et al. (13) reminded us of another key advantage of the transpapillary puncture. The existence of the circumpapillar sphincter of Henle, which plays a major role in hemostasis, as it contracts when the nephroscope or the nephrostomy tubes are removed.

Choosing a correct trans-papillary puncture site is mandatory, not only for hemorrhage prevention, but because an adequate tract through the parenchyma will provide a better support of the nephroscope during the surgery, and it will help to prevent the development of urinary fistulas.

On the other hand, recent publications by Liatsikos et al. (14) and Kyriazis et al. (15) support the safety of a puncture and dilation along an infundibulum or in a medial, closer to the renal pelvis zone. The authors describe their experience and results, with a $5 \%$ global transfusion rate, although a $25 \%$ bleeding-transfusion and development of urinary leak was observed in staghorn calculi procedures when even three different accesses were needed. As we know, this goes against the recommendations of Sampaio et al. (10-12), and the risk of arterial injury seems more evident. A closer-to-the-pelvis puncture puts at risk the integrity of major renal vessels, and if a percutaneous embolization is needed, the parenchymal damage will be significantly worse.

\section{Preoperative evaluation}

An adequate preoperative evaluation involves a complete anatomical imaging study with an intravenous urography computerized tomography (CT-IVU). This is mandatory to establish the primary calyx of the puncture through which the majority of the stone will be cleared, and to decide if additional tracts or a combined approach will be needed. A proper CT-UVI will help us to identify all the adjacent structures related to the kidney (colon, liver, spleen, pleura), and if any anatomical abnormalities are present in order to minimize as much as possible the risk of injuries.

Secondary tracts are usually created in separated calyces in which stones are unlikely to be cleared through the primary tract. Complete blood and urine analyses, with a urine culture like any other endourological surgery, are part of a correct preoperative evaluation.

\section{Prone puncture techniques}

Obtaining a safe and precise percutaneous renal access is the hallmark of a good percutaneous surgery. The most known methods for prone percutaneous puncture of the collecting system such as the "bull's eye" technique (also called "eye of the needle"), the "triangulation" technique, and the Escovar technique (13) (very popular and widely used in South America), depend in almost all cases on the guidance of fluoroscopy.

Recently, Sharma et al. (16) proposed a new technique, in which although some triangulation is used, they manage to mark on the skin the exact point where the target calyx is visualized under the $\mathrm{C}$-arm at $0^{\circ}$ and at $30^{\circ}$. They use these marks to calculate the deepness of the calyx and the needle inclination required for puncture.

Another widely-used method is the ultrasound-guided puncture, with the advantage of reducing fluoroscopy use and radiological exposure to the surgeon and to the patient. The use of abdominal ultrasound (US) gives us the advantage of measuring in real time the deepness of the puncture and adjacent structures (17).

If we only use the C-arm, we cannot localize the target calyx deepness with accuracy, thus we ignore the correct inclination of the puncture needle. US images can help us guide our needle to the desired target calyx, but the reassurance of the direction must always be made and corrected appropriately with the C-arm. In other words, if we only guide our puncture by US, we will access the urinary tract, but not necessarily through the papilla. In conclusion, the combination of the longitudinal orientation across the calyx-infundibulum-pelvis axis and the inclination of the puncture according to the deepness seen in US, allows us to perform a correct puncture into the target calyx 

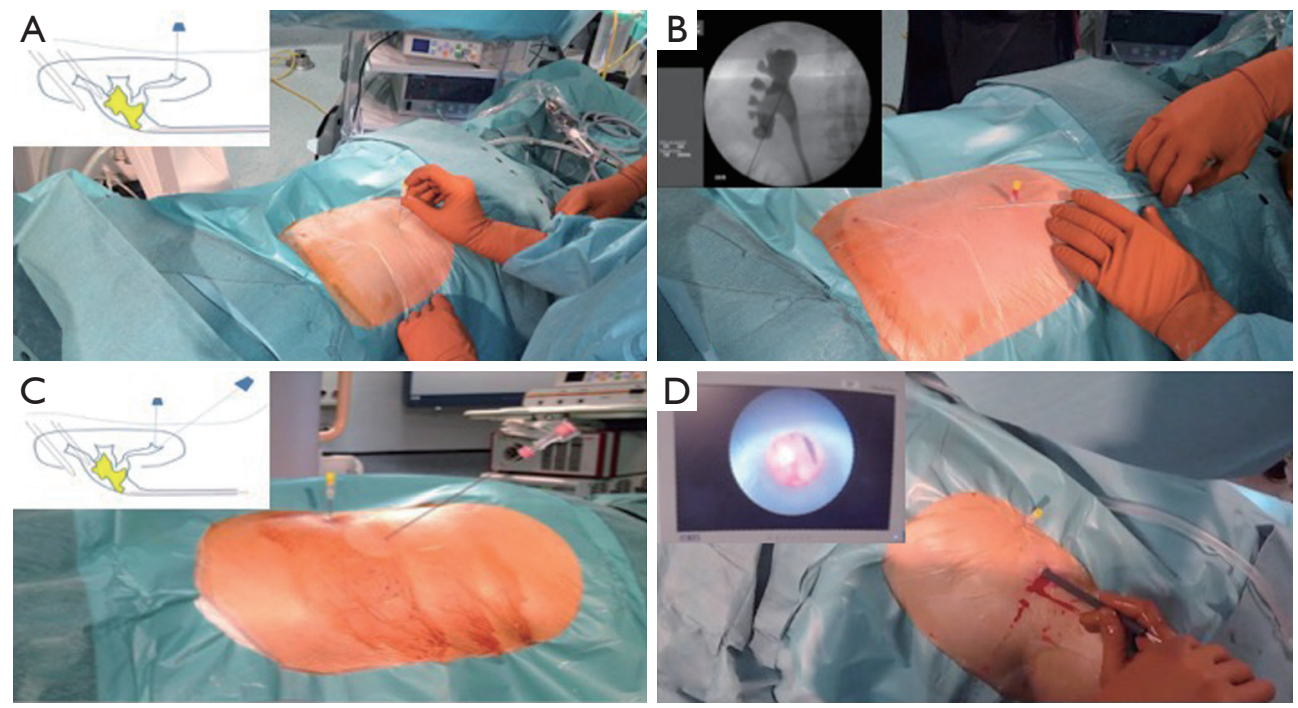

Figure 1 Needle-kiss technique. (A) perpendicular-to-the-skin puncture with $20 \mathrm{G}$ needle into the target calyx; (B) positioning the $18 \mathrm{G}$ needle over the skin to set correct direction; (C) puncture of the $18 \mathrm{G}$ needle through the papilla into the target calyx to join the $20 \mathrm{G}$ needle tip; (D) nephroscopic view of the $20 \mathrm{G}$ needle during percutaneous surgery demonstrating perfect alienation.

in almost every case.

More recently, a small minority of urologist are performing an alternative technique known as endoscopic guided access to facilitate retrograde or antegrade punctures (18). And one of the most novel trends is the X-ray free US-guided PCNL, in which the puncture and dilation are realized only with US guidance, as in the case of a nephrostomy tube placement. Authors conclude that the ideal patient who will not require the help of fluoroscopy, is the one with hydronephrotic kidneys and no staghorn lithiasis; and that starting the procedure with the intention to use US guidance eliminates a significant amount of radiation exposure $(19,20)$.

If by any circumstance, US is not available in the operating room at the time of puncture, a method that allows us to efficiently and exactly calculate the deepness of the target calyx, is the one we perform in our service (21). We herein describe our technique for prone percutaneous puncture.

Under general anesthesia, a 7-Fr ureteric catheter is placed for instillation of contrast or saline, which helps to opacify and distend the pelvicalyceal system in order to guide our percutaneous puncture to the target calyx. The ureteric catheter can serve as a medial reference point during dilation of the PCNL tract, and it helps to detect inadvertent migration of fragments through the ureter.

The patient is then positioned under the prone position. This maneuver must be done properly in order to avoid serious injuries, the staff involved in the operating room must be trained and act in coordination with the anesthesiologist who is managing the airway and endotracheal tube. Patients with cervical spine pathology, Down's syndrome or rheumatoid arthritis are at the greater risk of cervical injury (22) and special care should be taken. Protective pads are placed under the chest, shoulders, arms, knees, and ankles to prevent decubitus injuries, and a pillow should be placed under the abdomen in order to try to fix the kidney.

Contrast is passively instilled through the ureteric catheter, and with the $\mathrm{C}$-arm in the upright position (with $90^{\circ}$ angulation) the collecting system is inspected and the target calyx is selected.

We perform a perpendicular puncture with a fine spinal needle $(20 \mathrm{G})$ into the target calyx under fluoroscopic guidance (Figure 1A). We can measure the exact depth of the target calyx based on the length of the needle outside from the skin. When this first puncture is correctly performed, three signs can be observed:

* The intra-calyceal contrast viewed in the retrograde pyelography moves (fovea effect), this occurs when the needle is penetrating into the calyx;

- Urine or contrast output occurs immediately when removing the inner plug of the needle;

* The subtle movement of the needle from side to side 
"drags" the urinary tract, which is perfectly seen by fluoroscopy.

Now, we use an $18 \mathrm{G}$ needle to create the desired calyxinfundibulum-pelvis tract (Figure 1B). The inclination of this puncture according to the skin will be different in every case and, must be based on the depth of the $20 \mathrm{G}$ needle. As the deepness of the $20 \mathrm{G}$ needle tip will inform us the exact deepness of the target calyx, if a deep calyx is punctured, we need to broaden the puncture angle of the $18 \mathrm{G}$ needle with respect to the horizontal plane of the patient. On the other hand, if the target calyx is more superficial or closer to the skin, we should puncture the $18 \mathrm{G}$ needle in a more acute angle (Figure 1C).

When the $18 \mathrm{G}$ needle is correctly positioned into the target calyx, urine or contrast output are observed after removing the stylet.

The final outcome is to put together both tips of the needles inside the target calyx, thus called: "needle-kiss" technique or at least join them together as much as possible. The exact moment that the $18 \mathrm{G}$ needle "kisses" the $20 \mathrm{G}$ needle, we assure that the percutaneous tract is correctly performed (Figure 1D).

If difficulties in joining both tips inside the target calyx easily are experienced, we can slide the $\mathrm{C}$-arm at $30^{\circ}$ below the operating table. With this maneuver, we will observe from a different angle if the $18 \mathrm{G}$ needle is below the reference $20 \mathrm{G}$ needle, meaning that the initial puncture angle is incorrect. At the same time, guided by the $\mathrm{C}$-arm we can easily re-direct the puncture removing gradually the $18 \mathrm{G}$ needle and performing a more superficial puncture. In a similar way, we would have to do the opposite correction procedure if our $18 \mathrm{G}$ needle tip is above the reference needle tip.

\section{Benefits of prone puncture and prone PCNL}

Traditionally PCNL is done in the prone position, which allows a direct access to the posterior calyx, and provides a safer procedure regarding the location of the bowel. PCNL can also be done in the supine position, with its own advantages and disadvantages.

Supporters of the supine position for PCNL advocate that it is less demanding on patients with respiratory or cardiac pathology, that the downward direction of the track and sheath helps with spontaneous drainage of fragments, and that working at lower pressures may result in less fluid absorption (23). So far, these perceived advantages have not shown clinical superiority when compared with the prone approach (24-37). Drawbacks observed in the supine technique such as a restricted working space, difficulty in performing upper pole puncture, and awkward rigid nephoscope manipulation requiring in several cases complementary flexible nephroscopy, have limited its universal adoption (38). Moreover, there is recent data that showed no differences in peak inspiratory pressure when comparing patients in prone versus supine position (39). Some of the following benefits are not exclusive of the prone puncture but are considered an advantage when this position is used (40).

\section{Possibility of puncturing almost any urinary tract regarding abnormal anatomy}

Due to the multiple possible puncture sites, we can easily adapt the puncture in cases of unfavorable anatomy (e.g., ectopia, horseshoe kidney, rotated kidney, hepatomegaly, splenomegaly, scoliosis, etc.).

As the prone puncture tract is more posterior than the supine, in the rare cases that the colon is injured, a conservative management is feasible. Lateral and anterior punctures are more likely to cause intraperitoneal colonic injuries that require exploration and surgical management.

Some studies published in the seventies showed that right kidneys are more likely to be in a Brödel type orientation with more "opened calyx", while left kidneys are more likely to be in a Hodson type orientation with a more acute angle for a correct puncture (Figure 2). When aiming to perform a right or left prone puncture with the former considerations, we have space enough to choose correctly the puncture site to go through the renal papilla.

\section{Possibility to perform several tracts}

Although single tract PCNL is an efficient procedure to clear most renal stones (41), the use of multiple tracts is safe and effective and, could be considered as a feasible option for massive staghorn calculi (42). "Torquing" a rigid nephroscope in the attempt to reach a different calyx is the single most important cause of bleeding during PCNL and is largely responsible for increasing transfusion rates and urine extravasation (42). Moreover, Aron et al. (42) conclude there is no correlation between the number of tracts used and the drop of hemoglobin and need for transfusion when multiples tracts where needed in prone PCNL. 


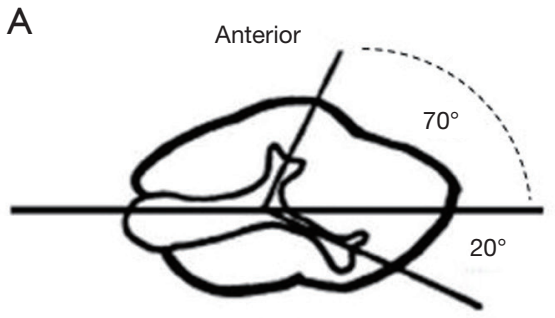

Posterior
B

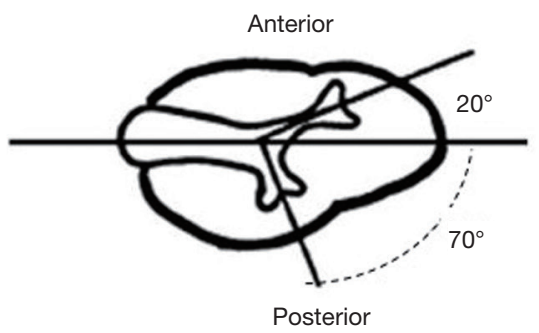

Figure 2 Caliceal anatomy. (A) Brödel model, more frequent in right kidneys; (B) Hodson model, more frequent in left kidneys.

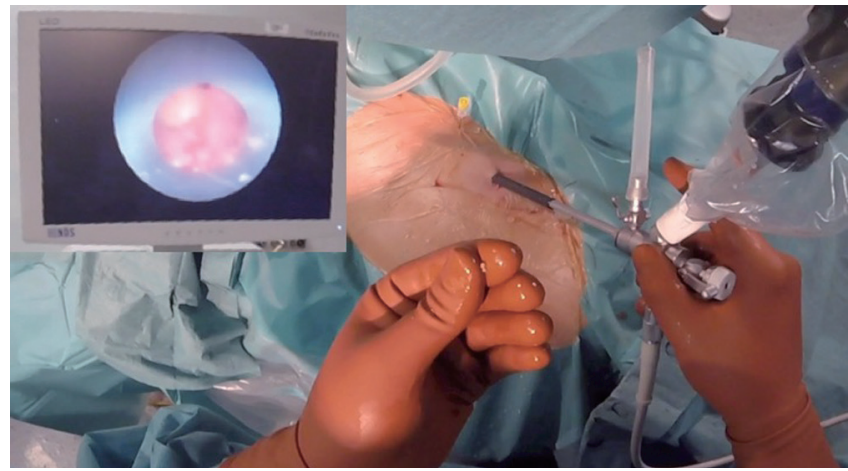

Figure 3 Vacuum cleaner effect during prone percutaneous lithotomy, endoscopic and surgeon's view.

The use of the vacuum cleaner effect for removal of fragments

A key benefit of the Minimally Invasive PCNL (MIP) (Karl Storz $^{\circledR}$ ) is the Bernouilli-(Vacuum cleaner)-effect. Vacuum cleaner effect is based on Bernoulli's principle, it mimics a mechanical forceps-like and invisible grasper and cannot be seen as a simple wash-out-phenomenon (43). This hydrodynamic effect allows to evacuate small stone fragments directly through the space created between the optic channel and the sheath, avoiding the need of excessive basketing and allows working at low pressures (44).

At our center, we simulate this effect in a different way, optimizing the stone fragment expulsion by using only the optic of a $26 \mathrm{Ch}$ nephroscope, which pass smoothly through a $22 \mathrm{Ch}$. Amplatz sheath. The small stone fragments escape through the lower semicircunference of the Amplatz sheath even at low pressures (21) (Figure 3).

\section{Upper calyx approach}

When aiming to perform a transpapillary puncture through the upper calyx, the prone position facilitates the puncture
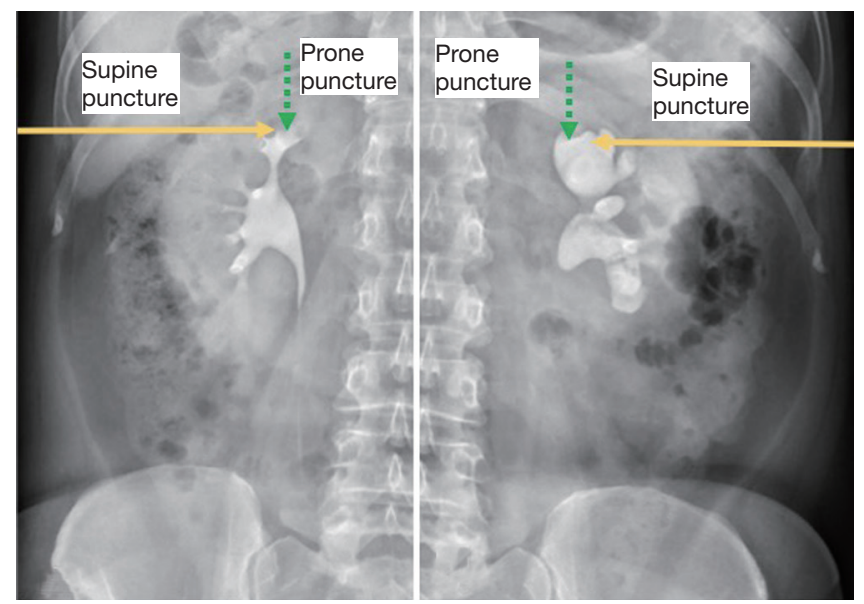

Figure 4 Puncture of the upper calyx scheme, differences between supine and prone approach.

of the renal papilla, avoiding a lateral puncture through the infundibulum (Figure 4).

\section{Ease of exploring the upper calyx through the inferior calyx}

One of the most complex maneuvers in PCNL is accessing the upper calyx through an inferior calyx access. This maneuver can be accomplished in the prone position as it is shown on fluoroscopic images on Figure 5.

\section{Possibility to perform endoscopic combined intrarenal surgery (ECIRS)}

Numerous publications have demonstrated that ECIRS, one of the greatest novelties in percutaneous surgery during the last years, is feasible, efficacious, and safe in the prone position (45-47).

At our center, when a combined approach is performed, 


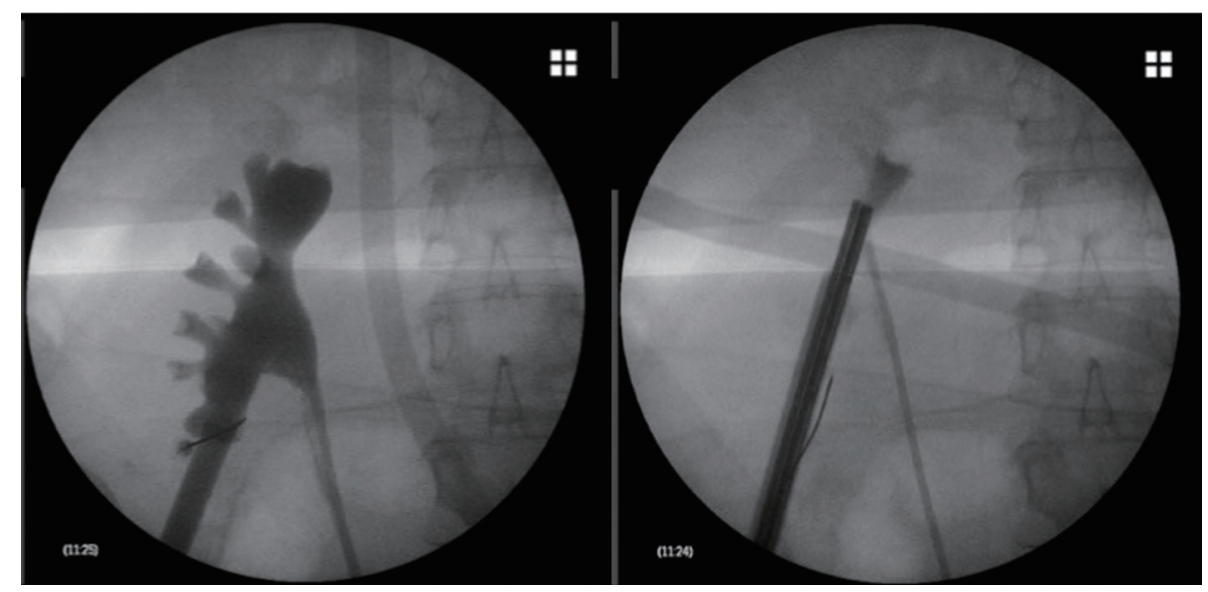

Figure 5 Exploration of upper calyx through inferior calyx approach in the prone position.

we change the ureteric catheter for a ureteric access sheath after the prone puncture is performed, just as in the supine position ECIRS technique (Figure 6).

\section{Possibility to perform a bilateral PCNL without modifying position}

The management of bilateral renal calculi safely remains a challenge for the endourologist. The feasibility of simultaneous bilateral PCNL (SBPCNL) in the prone position has been described in the recent literature, it has been shown to be a safe and efficacious treatment option, with similar complication rates than PCNL in a staged manner (48-56).

Some of the advantages of SBPCNL include: single anesthesia, single surgical and psychological stress, reduced operative time, less medication and shorter hospital stay, with the obvious cost implications (57).

\section{Possibility of performing PCNL under local anesthesia}

Normally, this procedure is performed under general or regional anesthesia. In the past years, due to improvements in experience and technique, many urologists have gained experience in using local anesthesia for performing PCNL. The procedure has been reported to be feasible and to provide satisfactory positive clinical outcomes in selected patients by multiple authors (58-61).

\section{What does the future hold for prone procedures?}

The prone position is the traditionally used position for
PCNL, and globally the most used approach (62), yet, it is logical that both prone and supine PCNL will become even over time, assuming that the supine procedure is an excellent alternative. At the present time, no technique is infallible because none can reach a steady stone-free rate of $100 \%$. A comprehensive overview of the outcome of the CROES PCNL Global Study concluded that although the supine position claimed to be favorable over the prone approach, it associated longer operative times, higher chance of a failed procedure and lower stone-free rates $(24,62)$.

We believe that in the future, prone PCNL will develop more scientific literature and case series in BSPCNL and miniaturization improvements, with smaller calibers and flexible miniaturized instruments like the actual pediatric nephroscope (fine as a flexible ureteroscope and short as a cystoscope or a nephroscope) minimizing the need for multiple percutaneous tracts.

\section{Conclusions}

We must keep in mind that in the future, supine PCNL training can increase its popularity worldwide, but an adequate training should be as much complete as possible, due to the own advantages of each technique. In scenarios in which the patients' anatomy is not feasible for a supine puncture access, the knowledge and experience in performing a prone puncture is mandatory. And in even more complex cases, when complex urinary tract anatomy is found (e.g., duplicated collecting system), an ECIRS wither in the prone or supine position should be considered. Teaching programs must focus on developing 


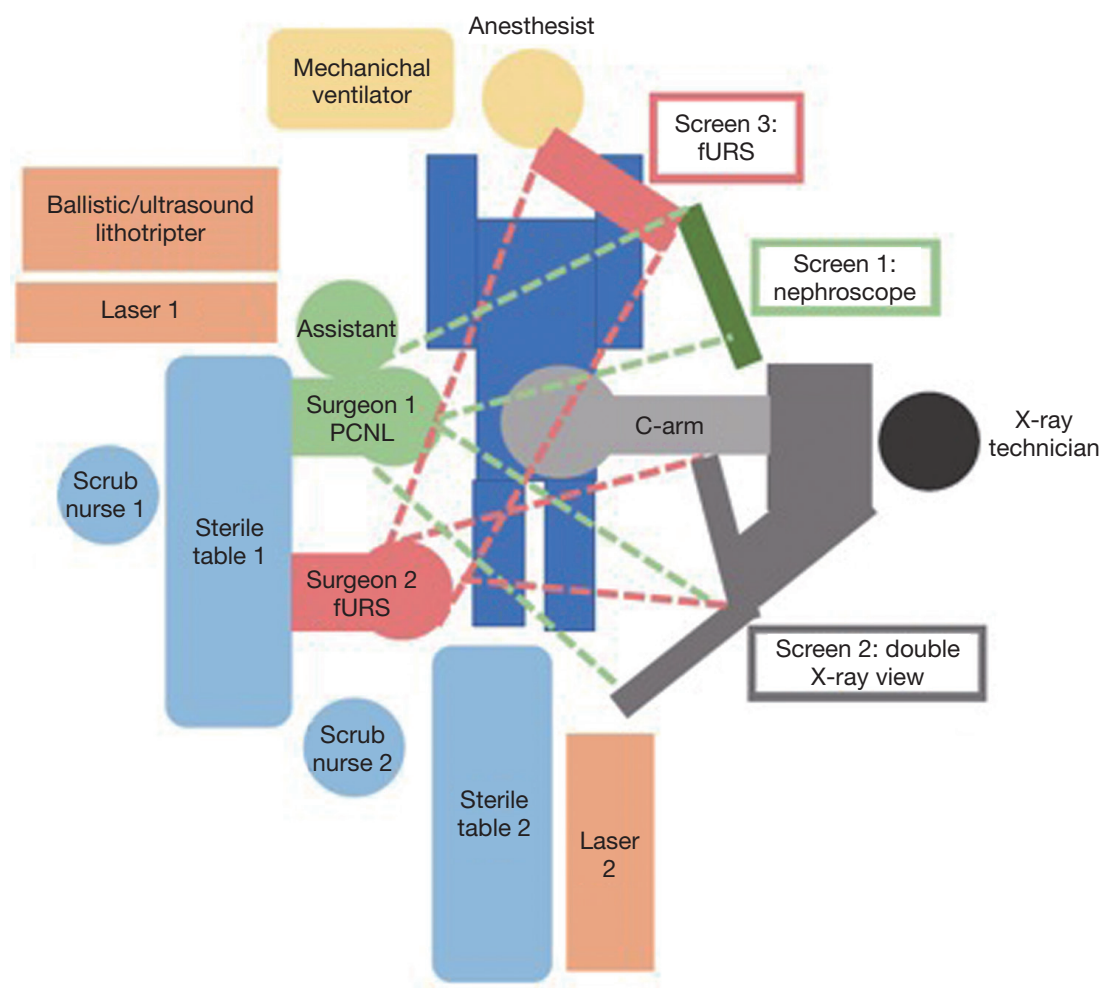

Figure 6 Prone ECIRS operating room setting. Surgeon 1 performs PCNL and surgeon 2 performs fURS. ECIRS, endoscopic combined intrarenal surgery; PCNL, percutaneous nephrolithotomy; fURS, flexible ureterorenoscopy.

both techniques together; putting aside the misconception that one technique is superior to the other. A puncture technique, either for supine or prone PCNL must be done with safety and accuracy, minimizing the number of attempts and radiologic exposure. The technique described in the present paper, the "needle-kiss" technique for prone percutaneous access, is safe and reproducible and allows us to work in the absence of a US machine aside. The final choice of the patient position should be tailored to each individual patient characteristics and the surgeon's preference in order to maximize the advantages of the technique.

\section{Acknowledgements}

None.

\section{Footnote}

Conflicts of Interest: The authors have no conflicts of interest to declare.
Ethical Statement: Ethics application and approval were not required to conduct this review and written informed consent was obtained from all patients who appear in pictures and figures.

\section{References}

1. Fernström I, Johansson B. Percutaneous pyelolithotomy. A new extraction technique. Scand J Urol Nephrol 1976;10:257-9.

2. Alken P, Hutschenreiter G, Günther R, et al. Percutaneous stone manipulation. J Urol 1981;125:463-6.

3. Segura JW, Patterson DE, LeRoy AJ, et al. Percutaneous removal of kidney stones: review of 1,000 cases. J Urol 1985;134:1077-81.

4. Smith AD, Reinke DB, Miller RP, et al. Percutaneous Nephrostomy in the Management of Ureteral and Renal Calculi. Radiology 1979;133:49-54.

5. Castaneda-Zuniga WR, Clayman R, Smith A, et al. Nephrostolithotomy: percutaneous techniques for urinary calculus removal. AJR Am J Roentgenol 1982;139:721-6. 
6. Türk C, Petřík A, Sarica K, et al. EAU Guidelines on Interventional Treatment for Urolithiasis. Eur Urol 2016;69:475-82.

7. Assimos D, Krambeck A, Miller NL, et al. Surgical Management of Stones: American Urological Association/ Endourological Society Guideline, PART II. J Urol 2016;196:1161-9.

8. Albala DM, Assimos DG, Clayman RV, et al. Lower pole I: a prospective randomized trial of extracorporeal shock wave lithotripsy and percutaneous nephrostolithotomy for lower pole nephrolithiasis-initial results. J Urol 2001;166:2072-80.

9. Turna B, Raza A, Moussa S, et al. Management of calyceal diverticular stones with extracorporeal shock wave lithotripsy and percutaneous nephrolithotomy: long-term outcome. BJU Int 2007;100:151-6.

10. Sampaio FJ, Aragao AH. Anatomical relationship between the intrarenal arteries and the kidney collecting system. J Urol 1990;143:679-81.

11. Sampaio FJ, Zanier JF, Aragão AH, et al. Intrarenal access: 3-dimensional anatomical study. J Urol 1992;148:1769-73.

12. Sampaio FJ, Mandarim-De-Lacerda CA, De Aragão AH. The collector system of the kidney. Applied anatomy based on the analysis of 3-dimensional casts. J Urol (Paris) 1987;93:183-5.

13. Escovar Díaz PA, Escovar La Riva PE, Rodríguez Escovar FP, et al. Percutaneous nephrolithotomy (PCNL): Conditions for a safe performance. Arch Esp Urol 2017;70:173-95.

14. Liatsikos EN, Kapoor R, Lee B, et al. "Angular Percutaneous Renal Access". Multiple Tracts Through A Single Incision for Staghorn Calculous Treatment in A Single Session. Eur Urol 2005;48:832-7.

15. Kyriazis I, Kallidonis P, Vasilas M, et al. Challenging the wisdom of puncture at the calyceal fornix in percutaneous nephrolithotripsy: feasibility and safety study with 137 patients operated via a non-calyceal percutaneous track. World J Urol 2017;35:795-801.

16. Sharma G, Sharma A. Determining the angle and depth of puncture for fluoroscopy-guided percutaneous renal access in the prone position. Indian J Urol 2015;31:38.

17. Knoll T, Michel MS, Alken P. Surgical Atlas Percutaneous nephrolithotomy: the Mannheim technique. BJU Int 2007;99:213-31.

18. Sivalingam S, Cannon ST, Nakada SY. Current practices in percutaneous nephrolithotomy among endourologists. J Endourol 2014;28:524-7.
19. Usawachintachit M, Tzou DT, Hu W, et al. X-ray-free Ultrasound-guided Percutaneous Nephrolithotomy: How to Select the Right Patient? Urology 2017;100:38-44.

20. Chi T, Masic S, Li J, et al. Ultrasound Guidance for Renal Tract Access and Dilation Reduces Radiation Exposure during Percutaneous Nephrolithotomy. Adv Urol 2016;2016:3840697.

21. Cansino R, Portilla A, Rivas JG. Performing easy prone punction. Cent European J Urol 2017;70:170-4.

22. Edgcombe H, Carter K, Yarrow S. Anaesthesia in the prone position. Br J Anaesth 2008;100:165-83.

23. Sofer M, Giusti G, Proietti S, et al. Upper Calyx Approachability through a Lower Calyx Access for Prone Versus Supine Percutaneous Nephrolithotomy. J Urol 2016;195:377-82.

24. Valdivia JG, Scarpa RM, Duvdevani M, et al. Supine versus prone position during percutaneous nephrolithotomy: a report from the clinical research office of the endourological society percutaneous nephrolithotomy global study. J Endourol 2011;25:1619-25.

25. De Sio M, Autorino R, Quarto G, et al. Modified supine versus prone position in percutaneous nephrolithotomy for renal stones treatable with a single percutaneous access: a prospective randomized trial. Eur Urol 2008;54:196-202.

26. Al-Dessoukey AA, Moussa AS, Abdelbary AM, et al. Percutaneous nephrolithotomy in the oblique supine lithotomy position and prone position: a comparative study. J Endourol 2014;28:1058-63.

27. Karami H, Mohammadi R, Lotfi B. A study on comparative outcomes of percutaneous nephrolithotomy in prone, supine, and flank positions. World J Urol 2013;31:1225-30.

28. Wang Y, Wang Y, Yao Y, et al. Prone versus modified supine position in percutaneous nephrolithotomy: a prospective randomized study. Int J Med Sci 2013;10:1518-23.

29. Basiri A, Mirjalili MA, Kardoust Parizi M, et al. Supplementary X-ray for ultrasound-guided percutaneous nephrolithotomy in supine position versus standard technique: a randomized controlled trial. Urol Int 2013;90:399-404.

30. Zhan HL, Li ZC, Zhou XF, et al. Supine lithotomy versus prone position in minimally invasive percutaneous nephrolithotomy for upper urinary tract calculi. Urol Int 2013;91:320-5.

31. Falahatkar S, Moghaddam AA, Salehi M, et al. Complete supine percutaneous nephrolithotripsy comparison with 
the prone standard technique. J Endourol 2008;22:2513-7.

32. Mazzucchi E, Vicentini FC, Marchini GS, et al.

Percutaneous nephrolithotomy in obese patients: comparison between the prone and total supine position. J Endourol 2012;26:1437-42.

33. McCahy P, Rzetelski-West K, Gleeson J. Complete stone clearance using a modified supine position: initial experience and comparison with prone percutaneous nephrolithotomy. J Endourol 2013;27:705-9.

34. Astroza G, Lipkin M, Neisius A, et al. Effect of supine vs prone position on outcomes of percutaneous nephrolithotomy in staghorn calculi: results from the Clinical Research Office of the Endourology Society Study. Urology 2013;82:1240-4.

35. El-Assmy AM, Shokeir AA, El-Nahas AR, et al. Outcome of Percutaneous Nephrolithotomy: Effect of Body Mass Index. Eur Urol 2007;52:199-204.

36. Sanguedolce F, Breda A, Millan F, et al. Lower pole stones: prone PCNL versus supine PCNL in the International Cooperation in Endourology (ICE) group experience. World J Urol 2013;31:1575-80.

37. Wang Y, Hou Y, Jiang F, et al. Percutaneous nephrolithotomy for staghorn stones in patients with solitary kidney in prone position or in completely supine position: a single-center experience. Int Braz J Urol 2012;38:788-94.

38. Duty B, Waingankar N, Okhunov Z, et al. Anatomical Variation Between the Prone, Supine, and Supine Oblique Positions on Computed Tomography: Implications for Percutaneous Nephrolithotomy Access. Urology 2012;79:67-71.

39. Siev M, Motamedinia P, Leavitt D, et al. Does Peak Inspiratory Pressure Increase in the Prone Position? An Analysis Related to Body Mass Index. J Urol 2015;194:1302-6.

40. Cracco CM, Alken P, Scoffone CM. Positioning for percutaneous nephrolithotomy. Curr Opin Urol 2016;26:81-7.

41. Shahrour K, Tomaszewski J, Ortiz T, et al. Predictors of Immediate Postoperative Outcome of Single-tract Percutaneous Nephrolithotomy. Urology 2012;80:19-25.

42. Aron M, Yadav R, Goel R, et al. Multi-Tract Percutaneous Nephrolithotomy for Large Complete Staghorn Calculi. Urol Int 2005;75:327-32.

43. Rassweiler J, Rassweiler MC, Klein J. New technology in ureteroscopy and percutaneous nephrolithotomy. Curr Opin Urol 2016;26:95-106.

44. Zanetti SP, Boeri L, Gallioli A, et al. Minimally invasive
PCNL-MIP. Arch Esp Urol 2017;70:226-34.

45. Hamamoto S, Yasui T, Okada A, et al. Endoscopic Combined Intrarenal Surgery for Large Calculi: Simultaneous Use of Flexible Ureteroscopy and MiniPercutaneous Nephrolithotomy Overcomes the Disadvantageous of Percutaneous Nephrolithotomy Monotherapy. J Endourol 2014;28:28-33.

46. Hamamoto S, Yasui T, Okada A, et al. Developments in the Technique of Endoscopic Combined Intrarenal Surgery in the Prone Split-leg Position. Urology 2014;84:565-70.

47. Lehman T, Bagley DH. Reverse lithotomy: modified prone position for simultaneous nephroscopic and ureteroscopic procedures in women. Urology 1988;32:529-31.

48. Soares RMO, Glaser AP, Cohen JE, et al. Bilateral Prone Percutaneous Nephrolithotomy Under Epidural in Candidate for Lung Transplant: Case Report and Review of Literature. J Endourol Case Rep 2018;4:5-8.

49. Nadler RB, Monk TG, Elashry O, et al. Simultaneous bilateral percutaneous nephrolithotomy with subarachnoid spinal anesthesia. J Endourol 1998;12:27-31.

50. Darabi MR, Soltani S, Akhavan Rezayat A, et al. Clinical outcomes of the simultaneous bilateral percutaneous nephrolithotomy (PCNL) in patients with kidney stones: A prospective cohort study. Electron Physician 2018;10:6377-82.

51. Pillai S, Mishra D, Sharma P, et al. Tubeless simultaneous bilateral percutaneous nephrolithotomy: safety, feasibility and efficacy in an Indian setting. Int J Urol 2014;21:497-502.

52. Holman E, Salah MA, Tóth C. Comparison of 150 simultaneous bilateral and 300 unilateral percutaneous nephrolithotomies. J Endourol 2002;16:33-6.

53. Holman E, Khan AM, Pásztor I, et al. Simultaneous bilateral compared with unilateral percutaneous nephrolithotomy. BJU Int 2002;89:334-8.

54. Ahlawat R, Banerjee GK, Dalela D. Bilateral simultaneous percutaneous nephrolithotomy. A prospective feasibility study. Eur Urol 1995;28:116-8.

55. Dushinski JW, Lingeman JE. Simultaneous bilateral percutaneous nephrolithotomy. J Urol 1997;158:2065-8.

56. Maheshwari PN, Andankar M, Hegde S, et al. Bilateral single-session percutaneous nephrolithotomy: a feasible and safe treatment. J Endourol 2000;14:285-7.

57. Wang CJ, Chang CH, Huang SW. Simultaneous bilateral tubeless percutaneous nephrolithotomy of staghorn stones: a prospective randomized controlled study. Urol Res 2011;39:289-94.

58. Dalela D, Goel A, Singh P, et al. Renal capsular 
block: a novel method for performing percutaneous nephrolithotomy under local anesthesia. J Endourol 2004;18:544-6.

59. Aravantinos E, Karatzas A, Gravas S, et al. Feasibility of percutaneous nephrolithotomy under assisted local anaesthesia: a prospective study on selected patients with upper urinary tract obstruction. Eur Urol 2007;51:224-7

60. Li H, Xu K, Li B, et al. Percutaneous Nephrolithotomy Under Local Infiltration Anesthesia: A Singlecenter Experience of 2000 Chinese Cases. Urology

Cite this article as: Carrion DM, Cansino JR, Quintana LM, Gómez Rivas J, Mainez Rodriguez JA, Pérez-Carral JR, Martínez-Piñeiro L. Prone percutaneous nephrolithotomy: its advantages and our technique for puncture. Transl Androl Urol 2018;7(6):950-959. doi: 10.21037/tau.2018.10.04
2013;82:1020-5.

61. Ecke TH, Barski D, Weingart G, et al. Presentation of a method at the Exploration Stage according to IDEAL: Percutaneous nephrolithotomy (PCNL) under local infiltrative anesthesia is a feasible and effective method - retrospective analysis of 439 patients. Int J Med Sci 2017;14:302-9.

62. Kamphuis GM, Baard J, Westendarp M, et al. Lessons learned from the CROES percutaneous nephrolithotomy global study. World J Urol 2015;33:223-33. 